Ege Tıp Dergisi / Ege Journal of Medicine 2018;57(4):222-227

\title{
Olweus öğrenciler için akran zorbalığı anketinin Türkçeye ve Türkiye'ye uyarlanması ve geçerlilik, güvenirlik analizi
}

\author{
Adoption of Olweus bully victim questionnaire to Turkish and Turkey and analysis of its \\ validity and reliability \\ Hilal Tıpırdamaz Sipahi ${ }^{1} \quad$ Ali Osman Karababa ${ }^{2}$ \\ ${ }^{1}$ Bornova İlçe Sağlık Müdürlüğü, Kamu Sağlık Hizmetleri Şubesi, İzmir, Türkiye \\ ${ }^{2}$ Ege Üniversitesi Tıp Fakültesi, Halk Sağlığı Anabilim Dalı, İzmir, Türkiye
}

\section{Öz}

Amaç: Bu çalışmada, Olweus öğrenciler için akran zorbalığı (OÖAZ) anketinin Türkçe formunun geçerlilik ve güvenirliğinin incelenmesi amaçlandı.

Gereç ve Yöntem: İlk aşamada anket Türkçeye çevrildi. Araştırmacılar ve çevirmenler tarafından ortak formun oluşturulmasından sonra, form iki ana dili olan bir çevirmen tarafından İngilizceye çevrildi. Anket geçerlilik çalışması sırasında yüzey ve kapsam geçerliliği açısından uzman panelinde değerlendirildi ve gerekli görülen değişiklikler yapıldı. Pilot çalışmanın ardından, anket İzmir ili Bornova ilçesi Milli Eğitim Müdürlüğü'ne bağlı ilköğretim okulları altıncı ve yedinci sınıflarını temsil eden 405 öğrenciye uygulandı (\%95 G.A., \%7,6 prevalans ve \%2,5 hata payı). Anketin güvenirliği Cronbach Alfa ve iki yarım test (Split Half) yöntemleriyle değerlendirildi.

Bulgular: Uzman paneli anketin kavramsal yapıyı karşıladığı ve literatüre uygun biçimde akran zorbalığının temel alanlarını içerdiği görüşünde birleşti. Geçerlilik ve güvenirlik çalışması 2008 yılı Nisan ayında Bornova'da sekiz ilköğretim okulundaki 6. ve 7. sınıflarda gerçekleştirildi. Araştırmaya katılan 405 öğrenciden OÖAZ anketini dolduran 400 öğrenci veri tabanına alındı. Anketin tümünün Cronbach Alfa değeri .81'di. Tek, çift sıralaması içinde SpearmanBrown iki yarım test güvenirlik katsayısı .85 olarak bulundu.

Sonuç: Çalışmanın bulguları, Olweus öğrenciler için akran zorbalığı anketinin Türkçe versiyonunun geçerlilik ve güvenirliğinin tatmin edici olduğunu göstermektedir. Anket akran zorbalığı araştırmalarında faydalı bir araç olarak kullanılabilir.

Anahtar Sözcükler: Akran zorbalığı, anket, geçerlilik, güvenirlik, okul.

\section{Abstract}

Aim: In this study it was aimed to determine the reliability and validity of the Olweus bully victim questionnaire (OBVQ) in Turkish.

Materials and Methods: In the first step the questionnaire was translated to Turkish. Afterwards the final form of the questionnaire was formed by the researchers and translators. The final form of the questionnaire was translated to English by a translator who had two native languages. Content and surface validity was evaluated by a specialist panel and changes made which are needed. After the pilot survey, the questionnaire was applied to 405 students which presented Izmir Bornova primary schools 6 and 7 th grade classes (95\% Cl, 7.6\% prevalence, 2.5\% error). The reliability of the questionnaire was evaluated by Cronbach Alpha and split half tests.

Results: The panel agreed on that the questionnaire comprised the content of bullying and its basic aspects in concordance with the literature. Validity and reliability study was conducted in the sixth and seventh classes of eight primary schools located in Bornova-Izmir in April 2008. Of 405 students, data of 400 who filled the questionnaire was included in the database. Cronbach Alpha coefficient of the whole questionnaire was .81. Spearman-Brown split half reliability in odds, even ranks score was 85 .

Conclusion: These findings show that the validity and the reliability of Turkish version of OBVQ are satisfactory. The questionnaire may be used as a useful tool for bullying research.

Keywords: Bullying, questionnaire, validity, reliability, school.

Yazışma Adresi: Hilal Tıpırdamaz Sipahi

Bornova İlçe Sağlık Müdürlüğü, Kamu Sağlık Hizmetleri Şubesi, İzmir, Türkiye

Makalenin Geliş Tarihi: 03.08.2017 Kabul Tarihi: 26.12.2017 


\section{Giriş}

Akran zorbalığı öğrenciler arasında genellikle bir güç dengesizliği zemininde gelişen, tekrarlayıcı tarzda, isim takma, alay etme, küçük düşürme, tehdit etme, dışlama ve fiziksel zarar verme gibi çok çeşitli davranışları kapsayan bir şiddet türüdür (1-4). Bilimsel literatürde Dan Olweus'un 1970'li yıllarda yaptığı çalışmalar ile yer almaya başlamıştır (5). Günümüzde dünyanın her ülkesinde bu sorunla karşılaşılmaktadır. Çocukluk çağında sıklığı yaşa, bölgeye, ülkeye göre büyük değişkenlik göstermekle birlikte yaşantılayanlarda, hem o sırada, hem de geleceklerinde çeşitli izler bırakır $(1,3,6,7)$. Akran zorbalığına maruz kalan ve zorbalık yapan çocuklarda depresyon, intihar düşünceleri, psikiyatrik problemler, ebeveynlerle ilişkide sorunlar ve akademik alanda problemler daha sık görülmektedir $(8,9)$. Zorbalarda erişkin yaşa geldiklerinde davranış bozuklukları ve yarısından çoğunda suça eğilim ortaya çıkmaktadır $(1,6,7)$.

Uzun yıllardır gelişmiş ülkelerin eğitim sistemlerinde akran zorbalığı ile ilgili mücadele önemli bir yer tutmaktadır $(1,6)$. Ülkemizde konu otuz yıllık bir gecikme ile 2000'li yıllarda incelenmeye başlanmıştır (10). Sorun ancak okullarda çok ciddi yaralanmalar ya da ölümler görüldüğünde, kısa süreliğine toplumun ilgisini çekmektedir. Türkiye'de konu ile ilgili yayınlanmış veri ise her geçen gün artmaktadır (10-19).

$\mathrm{Bu}$ çalışmada Olweus öğrenciler için akran zorbalığı (OÖAZ) anketinin Türkçeye ve Türkiye'ye uyarlanarak, geçerlilik, güvenirlik analizinin yapılması, konu hakkında çalışma yapmak isteyenlere uluslararası alanda da kabul görmüş bir ölçüm aracı sunulması amaçlanmıştır.

\section{Gereç ve Yöntem}

Araştırma kesitsel, analitik düzende bir alan çalışmasıdır.

\section{Olweus öğrenciler için akran zorbalığı anketi}

İlk ve orta öğretim öğrencilerindeki akran zorbalığını ölçmek amacıyla 1996 yılında Dan Olweus tarafından oluşturulan Revised Olweus Bully/Victim Questionnaire [Olweus Öğrenciler İçin Akran Zorbalığı (OÖAZ) Anketi] 8 -16 yaş grubundaki üçüncü sınıf ve lise çağı arasındaki öğrenciler için geliştirilmiştir. Otuz dokuz maddeden oluşan Likert tipi bir ankettir. Anketin başında akran zorbalığının detaylı tanımı bulunur. Anketteki zaman aralığı ya da referans periyot öğrencilerin doğal hafızası açısından çok uzun olmayan bir süreci (geçtiğimiz aylarda ...) içermektedir. Buradaki "geçtiğimiz aylarda" yaz ya da sömestr tatili sonrasında okulun başlamasıyla anketin uygulanması arasındaki süreci işaret etmektedir. $\mathrm{Bu}$ süre en az altı ya da sekiz hafta olmalıdır. Ankette akran zorbalığına konu olan davranışlar da çok açık önermelerle, ayrıntılı olarak açıklanarak sorgulanmaktadır. Ana soruların yanıt seçenekleri de oldukça net tanımlanmıştır; "geçtiğimiz aylarda bana bunlar olmadı / akran zorbalığı yapmadım", "sadece bir ya da iki kez oldu", "bir ay içinde 2 ya da 3 kez oldu", "ortalama haftada bir kez oldu", "Haftada birkaç kez oldu" gibi. Bu şıklar beş puanlık skala şeklinde kodlanacak biçimde tasarlanmıştır. Anket içindeki zorbalık tanımından sonra genel bir soru bulunmaktadır: "Geçtiğimiz aylarda okulda akran zorbalığına ne sıklıkta uğradın?". Sorudan sonra daha önce belirtilmiş olan beş şık gelmektedir. Anketin ikinci bölümünde aynı sorunun zorbalık yapma ile ilgili şekli de bulunmaktadır: "Geçtiğimiz aylarda okulda bir ya da birkaç öğrenciye akran zorbalığı yapılırken sen ne sıklıkta katıldın?". Bu iki genel sorudan sonra zorbalığın çeşitli formlarını (sözlü, fiziksel, indirekt, cinsel, siber vs.) sorgulayan dokuz ek soru bulunmaktadır (20).

\section{Anketin değerlendirmesi}

OÖAZ Anketi'nin zorba, kurban, zorba/kurban olmak açısından kestirim noktası sorgulanan eylemin "Bir ay içinde 2 ya da 3 kez veya daha sık" gerçekleşmesi olup, anketin 4-13. sorularında kestirim noktasının üstünde herhangi bir yanıtın işaretlenmiş olması kurban; 24-33. sorularda aynı koşulu sağlaması zorba; her iki bölümde yer alma ise zorba/kurban olarak nitelendirilmeyi getirirken, ilk iki grupta da yer almayanlar zorba ve kurban olmayanlar (ZVKO) olarak adlandırılır (20).

OÖAZ Anketi'nin Türkçeye uyarlama ve geçerlilik değerlendirilmesinde aşağıdaki yöntemler kullanıldı (21):

\section{a. Geçerlilik analizi}

Anketin yapı, kavram ve dil eşitliğinin sağlanması: Anketin yapı, kavram ve dil eşitliğinin sağlanmasında psikometrik ölçeklerin uyarlanmasında kullanılan uluslararası süreçlere uygun olarak aşağıdaki basamaklar izlenildi.

1. Anketi birbirinden bağımsız olarak, biri çift anadili olan üç çevirmen İngilizceden Türkçeye çevirdi. Aynı üç çevirmen ve araştırmacı farklı üç çeviriyi tek bir ortak Türkçe form haline getirdi.

2. Türkçe form çift anadili olan farklı bir çevirmen tarafından tekrar İngilizceye çevrildi.

3. Son olarak iki halk sağlığı profesörü, bir psikoloji profesörü, bir çocuk ve ergen ruh sağlığı uzmanı, bir rehber öğretmen ve araştırmacının katıldığı uzman panelinde orijinal form, Türkçe ve İngilizce formlar gözden geçirildi. Özgün ankette "Irk ve renk" ile ilgili madde Türkçe formda Olweus'dan izin alınarak "köken ve inanç" olarak değiştirildi. Bunun dışında uzmanlar anketin kavramsal yapıyı karşıladığı, literatüre uygun biçimde akran zorbalığının temel alanlarını içerdiği görüşünde birleşti. Uygun dil ve kavram düzeltmelerin ardından anketin Türkçe sürümü oluştu.

4. Pilot çalışma: Çalışma grubuna dahil olmayan Bornova Kars Halil Atilla I.Ö.O.'da, bir 6. sınıfta 20 öğrenci üzerinde, bir ders saatinde son haline getirilmiş OÖAZ anketinin pilot çalışması yapıldı. Pilot çalışma sonrasında herhangi bir değişikliğe gidilmesi gerekmedi. 


\section{b. Güvenirlik analizi}

Araştırma evrenini İzmir ili Bornova ilçesinde Bornova İlçe Milli Eğitim Müdürlüğü'ne bağlı engelli okulları dışındaki 62 resmi şehir ilköğretim okulunun 6 . ve 7 . sınıflarındaki 13.835 öğrenci oluşturdu. OÖAZ anketinin engellilerde kullanımıyla ilgili herhangi bir veri bulunmaması, özel okulların yönetici ve velileriyle öngörülen işbirliği güçlüğü, köy okullarında sadece ilk beş sınıfın olması nedeniyle engelli okulları, özel okullar ve köy okulları evrene dahil edilmedi.

Anket bu evrenden küme örnekleme yöntemiyle (\%95 G.A., \%7.6 prevalans ve \%2.5 hata payı) seçilen 405 öğrenciye 2008 yılı Nisan ayında İmir ili Bornova ilçesinde uygulandı, 400 öğrenci anketi doldurdu.

Anketin iç tutarlılığı Chronbach Alfa ve Split Half yöntemleriyle değerlendirildi. Olweus'un, anketten elde edilen sonuçların anketin kullanıldığı diğer çalışmalarla karşılaştırılabilir olabilmesi için, anketten soru çıkarılmamasını tavsiye etmesi ve buna gereksinim duyulmaması nedeniyle anketten soru çıkarılmadı.

Veri toplama yöntemi ve süresi

İzmir Valiliği'nden III Milli Eğitim Müdürlüğü kanalı ile alınan iznin ardından, araştırmacı tarafından okulların yöneticileriyle görüşülüp Nisan 2008'in son iki haftası için uygulama randevuları alındı ve çalışma grubundaki sınıflara gidilerek araştırma hakkında bilgi verildi. Ardından veli bilgilendirilmiş onam formu öğrencilere dağıtıldı ve uygulama gününde toplanacağı bildirildi.

Randevu gününde, uygulama saatinde öğretmen sınıftan çıkarıldı. Ardından o ders saatinde sınıfta bulunan öğrencilere öğrenci bilgilendirilmiş onam formu ve anket araştırmacı tarafından dağıtılarak, verdikleri yanıtların gizli tutulacağı, okul ya da aileden herhangi bir kişiyle paylaşılmayacağı bilgisi verildi. Aynı zamanda kendilerinin de arkadaşlarının yanıtlarına bakmamaları gerektiği, toplanan bilgilerin kişilere özel olduğu söylendi.

Akran zorbalığı kavramını okul çocuklarına doğru biçimde açıklamak ve anketin genel olarak anlaşımasını sağlamak amacı ile anketin başında yer alan akran zorbalığının detaylı tanımı öğrencilere araştırmacı tarafından sesli olarak okundu. Açıklamanın okunmasının ardından da anlaşılma durumu sözlü olarak kontrol edildi ve gerekli durumlarda örneklerle açıklama ayrıntılandırıldı. Anlaşılmayan noktalar örnek vererek tekrar açıklandı. Ardından öğrencilerin onayı alındıktan sonra bilgilendirilmiş onam formu, anketten ayrılarak toplandı. Öğrencilere soruları yanıtlamaları için bir ders saati verildi. Daha fazla zamana gereksinimi olan öğrenciler, dersi izleyen arada devam ederek formu tamamladılar.

\section{Etik açıklamalar}

OÖAZ anketinin geliştiricisi olan Dan Olweus'a kullanım hakkı için yazılı olarak başvuruldu. Olweus telif ücreti karşılığında ve araştırmanın sonuçlarından haberdar edilmesi kaydıyla, sadece bu çalışma için geçerli yazılı izin verdi. Araştırma için Ege Üniversitesi Tıp Fakültesi Araştırma Etik Kurulu'ndan 18.12.2007 tarih ve 07-12/7 karar numarası ile etik kurul onayı, İ Milli Eğitim Müdürlüğü kanalı ile 01.04.2008 tarih, 24712 sayılı valilik onayı alındı. Araştırmaya dahil olan öğrencilerin velileri, veli bilgilendirilmiş onam formunu; öğrenciler, öğrenci bilgilendirilmiş onam formunu doldurarak araştırmacıya teslim ettiler.

\section{Kullanılan istatistiksel yöntemler}

Tüm veriler SPSS 11.5 programı kullanılarak değerlendirildi. OÖAZ anketinin güvenirliği Cronbach alfa değeri ve Split Half yöntemi Spearman-Brown katsayısı ile hesaplandı.

\section{Bulgular}

Araştırma grubundaki toplam 400 öğrencinin 209'u altıncı sınıf, 191'i yedinci sınıf öğrencisiydi. Öğrencilerin yaşları 11-15 arasında olup yaş ortalamaları $12.51 \pm 0.73$ 'dü. Araştırma grubunun \%48.1'i kız, \%51.9'u erkek öğrencilerdi.

OÖAZ anketinde akran zorbalığına uğrama boyutunda değerlendirilen 11 madde; anket içinde sadece zorbalığa uğrama tiplerini ve sıklığını sorgulayan 4.-13. sorulardır. $\mathrm{Bu}$ sorularda kestirim noktasının üstünde herhangi bir yanıtın işaretlenmiş olması akran zorbalığına uğramayı getirir. Akran zorbalığı yapma boyutunda değerlendirilen 11 madde ise zorbalık yapma tiplerini ve sıklığını sorgulayan 24.-33. sorulardır; yine aynı koşulu sağlama akran zorbalığını yapmayı getirir. Anketin diğer maddeleri akran zorbalığı ile ilgili çeşitli tutumları ve özellikleri sorgular. Bu nedenle Cronbach alfa analizleri akran zorbalığına uğrama için 4.-13. sorularla, akran zorbalığı yapma için 24.-33. sorularla yapıldı (Tablo 1). Anketin tamamının Cronbach Alfa değeri .8094 (Standardize Cronbach Alfa=.8632) olarak bulundu.

İki yarım test güvenirlik analizlerinde anket maddeleri sıralı haliyle ikiye bölünerek analiz edildiğinde ilk ve ikinci yarım Cronbach Alfa değerleri sırasıyla .82, .54; Spearman-Brown katsayısı .64 bulundu. SpearmanBrown katsayısı ve ikinci yarım Cronbach Alfa değerinin yüksek olmamasının nedeni ikinci yarımda analize giren soruların içinde anketin iki farklı boyutuna ait soruların bulunması olarak düşünüldü (ikinci yirminin ilk üç ve son üç sorusu). Bunun üzerine Şencan'ın (21) önerdiği diğer yarıya bölme yöntemi, tek ve çift madde numaralarına göre anket maddeleri sıralanarak tekrar iki yarım analizi yapıldı. Bunun sonucunda Spearman-Brown katsayısı .85, ilk ve ikinci yarım Cronbach Alfa değerleri sırasıyla .69 ve .65 olarak bulundu (Tablo-2). 
Tablo-1. Olweus Öğrenciler için Akran Zorbalığı Anketinin Cronbach Alfa Değerleri.

\begin{tabular}{lcc}
\hline \multicolumn{1}{c}{ Analize alınan maddeler } & Madde sayısı & Cronbach Alfa değeri \\
\hline Akran zorbalığına uğrama (4-5-6-7-8-9-10-11-12-12a-13. sorular) & 11 & .8204 \\
Akran zorbalığı yapma (24-25-26-27-28-29-30-31-32-32a-33. sorular) & 11 & .8027 \\
Anketin tamamı & 39 & .8094 \\
\hline
\end{tabular}

Tablo-2. Olweus Öğrenciler İçin Akran Zorbalığı Anketinin İki Yarı (Split Half) Güvenirlik Analizi Sonuçları.

\begin{tabular}{lcc}
\hline \multicolumn{1}{c}{ Uygulanan güvenirlik analizleri } & Anketin birinci ve ikinci yarıları & Tek, çift sıralaması içinde \\
\hline İki yarı tutarlıı̆ı̆ arasındaki korelasyon & .4653 & .7438 \\
Guttman split half (iki yarı) katsayısı & .5997 & .8494 \\
Spearman-Brown iki yarı güvenirlik katsayısı & .6351 & .8531 \\
20 maddelik 1. yarı Cronbach Alfa değeri & .8198 & .6884 \\
19 maddelik 2. yarı Cronbach Alfa değeri & .5434 & .6500 \\
\hline
\end{tabular}

\section{Tartışma}

Bu çalışma ile Türkiye'de ilk kez OÖAZ anketinin geçerlilik-güvenirlik analizi yapılmış ve sonuçlar olumlu bulunmuştur. Akran zorbalığı dünyada 1970'li yıllarda ayrıntılı incelenmeye başlanan bir kavramdır (20). Bu kavramı ölçmek için kullanılan çeşitli yöntemlerin başlıcaları kendini bildirim ölçekleri, akran değerlendirme ve öğretmen değerlendirme ölçekleridir. Her bir yöntemin kendine özgü olumlu ve olumsuz yanları vardır $(7,10)$. Kendini bildirim ölçeklerinin yorumlanabilirlikleri ya da anlamları ve tekrar edilebilirlikleri prevalans çalışmaları açısından olumlu yanlarıdır (21). Bunun yanında büyük örneklemde düşük maliyetle değerlendirme yapmaya olanak tanırlar. İsimsiz veri toplanması yanıtların geçerliliğini arttırır, sosyal ilişkiler, aile ya da müdahale stratejileri ile ilgili bilgi verir ve uzman olmayanlar tarafından dahi uygulanabilirler. Ancak sonuçların güvenirliği ölçeği yanıtlayanların neyin ölçülmek istendiğini iyi anlamaları ve kendilerini dürüstçe ifade etmeleri gibi özelliklerle yakından ilişkilidir. Özellikle küçük çocuklar dikkatlerini uzun süre toplayamazlar ve daha önce verdikleri yanıtları unutabilirler. Ayrıca geriye dönük olmaları beraberinde doğru anımsama sorununu getirir (22). Akran ve öğretmen değerlendirme yöntemleri kişilerin bir ya da daha fazla özelliğe oturan kişileri belirlemesine dayanır. Akranların birbirlerini nasıl algıladıklarının sorgulanmasına verecekleri yanıtların duygusal gerçeklikten çok, kendi izlenim ve yorumlarını içerebilir olması akran bildirimlerinin sonuçlarını olumsuz etkileyebilir (21). Akran zorbalığının çoğunlukla erişkin gözetimi olmayan yerlerde ve zamanlarda gerçekleşmesi ve erişkinlerin duruma olan ilgilerindeki farklar öğretmenlerin bildiriminde olumsuz yönlerdir (22). Literatürde akran zorbalığını ölçmek için en sık kullanılan yöntem kendini bildirim türü ölçeklerdir (23).

Literatürde kendini bildirim türü ölçekler içinde OÖAZ Anketi'nin özellikli bir yeri vardır. Norveçli araştırmacı Dan Olweus uluslararası literatürde akran zorbalığı konusunda ilk çalışmaları yayınlayan, önde gelen bilim insanlarından biridir. Olweus önceki çalışmalarında kullandığı anketi 1996 yılında revize etmiştir. OÖAZ anketinin uluslararası literatürdeki yeri oldukça önemlidir ve Dünya Sağlık Örgütü'nün "okul çağındaki çocukların sağlıkla ilgili davranışları" başıkılı uluslararası çalışmasında da akran zorbalığını ölçmek için tercih edilmiştir (24).

İngilizcede bullying, mobbing gibi terimler olarak geçen "akran zorbalığı" kavramının tam bir Türkçe karşılığı yoktur. Akran zorbalığı kavramı Türkçe literatürde ilk kez Ercan ve ark. (25) tarafından 2000'de kullanılmıştır. Daha sonraki çalışmalarda kavram "zorbalık", "akran zorbalığı" olarak adlandırılmıştır $(14,16)$. İngilizce karşılığı bullying olan kavramı "akran istismarı" olarak kullanan kaynaklar da vardır (3). Bununla birlikte bu çalışmada çeviri ve yazım aşamasında bullying kavramı Türkçeleştirilirken, Türk literatüründe "zorbalık" çevirisinin daha sık yer alması ve "zorba, zorbalık" ve "istismar" kelimelerinin Türk Dil Kurumu Güncel Sözlük anlamları göz önünde bulundurularak "akran zorbalığı" tanımlaması tercih edildi.

Anketin yabancı dilden uyarlanmasında Şencan'ın önerdiği basamaklar izlendi (26). Geçerlilik çalışması sırasında ise anket yüzey ve içerik geçerliliği açısından değerlendirildi. Özgün ankette "ırk ve renk" kavramı bulunan madde; uzmanların köken ve inanca dair ayrımcılığın sorgulanmasının ülkemiz koşullarına daha uygun olduğuna karar vermeleri üzerine, Türkçe formda Olweus'dan izin alınarak "köken ve inanç" olarak değiştirildi. Uzmanlar anketin yüzey ve içerik geçerliliğinin yeterli olduğu konusunda fikir birliğine vardı.

Anketin güvenirliği değerlendirilirken iç tutarlılık için Cronbach Alfa ve iki yarım test yöntemleri kullanıldı. Anketin tamamının Cronbach Alfa değeri (.81) .80 - .90 arasında bulunduğundan güvenirliği yüksek olarak değerlendirildi (26). Olweus, anketin iç geçerliliğini test ederken 5000'den fazla öğrenci ile yaptığı çalışmada, zorbalığa uğrama için olan maddeleri ya da zorbalık 
yapma için olan maddeleri kendi içinde kombine ederek yaptığı analizin sonucunda anketlerin içerdiği maddelerin sayısına göre farklılaşmakla birlikte Cronbach Alfa değerlerini .80 ya da daha yüksek bulmuştur (27). Solberg ve Olweus (21) 2003 yılında yayınladıkları çalışmada Cronbach Alfa değerlerini akran zorbalığına uğrama için .88, akran zorbalığı yapmak için .87 değerlerini bildirmişlerdir. Bu çalışmada, Cronbach Alfa değeri anket iki alt başlıkta incelendiğinde akran zorbalığına uğrama için (11 madde) .8204 ve akran zorbalığı yapma için (11 madde) 8027 olarak bulundu (Tablo-1). Bu değerler Solberg ve Olweus'un bulguları ile uyumludur (21).

$\mathrm{Bu}$ çalışmada OÖAZ anketi akran zorbalığını değerlendiren bir başka araçla ya da ölçütle karşılaştırılmadı. Bu çalışmanın yapıldığı süreçte karşılaştırmada kullanılabilecek, geçerli ve güvenilir tek ölçek Pekel'in (16) "akran zorbalığı kurbanlarını ve zorbalarını belirleme ölçeği” idi. Ancak söz konusu ölçeğin kestirim noktası OÖAZ anketinden çok farklı olması nedeniyle karşılaştırma için kullanılması düşünülmedi.

Test-tekrar testi ya da öğretmen bildirimiyle korelasyon anketi anonim olarak uygulandığından yapılmadı.
Anketin geçerliği konusunda daha fazla bilgi sağlamak için ileriki çalışmalarda akran zorbalığını değerlendiren uygun başka araçlarla ilişkisinin incelenmesi önerilmektedir.

Öğrencilerin kendi bildirimlerini içermesi, akran zorbalığının prospektif olarak değerlendirilmemiş ya da ölçülmemiş olması, örnekleme özel okulların, yaşanabilecek işbirliği sorunları ön görülerek alınmaması çalışmanın sınırlııklarıdır. Diğer bir sınırılık öğrencilerin kendi bildirimlerini içermesidir. Bu durum şüpheyle karşılanabilir fakat öğrencilerin anketi anonim olarak doldurmaları verilen bilgilerin güvenilir olma olasılığını arttırmaktadır. Ayrıca öğrencilerin anketi doldurmasından önce akran zorbalığının kapsamlı bir tanımının yapılması göreceli daha nesnel sonuçlar elde edilmesine yardımcı olmaktadır.

\section{Sonuç}

Çalışmamızın bulguları Olweus öğrenciler için akran zorbalığı anketinin Türkçe versiyonunun tatmin edici psikometrik özelliklere sahip olduğunu doğrulamaktadır. Anket araştırmalarda, müdahale çalışmalarında ve izlemlerde akran zorbalığını değerlendirmek için kullanılabilecek yararlı bir araç olarak kullanılabilir.

\section{Kaynaklar}

1. Craig WM. The relationship among bullying, victimization, depression, anxiety and aggression in elementary school children. Pers Individ Dif 1998;24(1):23-130.

2. Espelage DI, Swearer SM. Research on school bullying and victimization: What have we learned and where do we go from here? School Psych Rev 2003;32(3):365-83.

3. Güvenir T. Okulda akran istismarı. Ankara: Kök Yayıncılık; 2008;51-55.

4. Mc Guckin C, Lewis CA. Experiences of school bullying in northern Ireland: Data from the life time and times survey. Adolescence 2006;41(4):313-20.

5. Olweus D. Aggression and peer acceptance in adolescent boys: Two short term longitudinal studies of ratings. Child Development 1977;48(4):1301-13.

6. Olweus D. Bullying at school. Oxford: United Kingdom, Blackwell Publishing; 2003.

7. Pişkin M. Okul zorbalığı, tanımı, türleri, ilişkili olduğu faktörler ve alınabilecek önlemler. Kuram ve Uygulamada Eğitim Bilimleri 2002;2(5):531-62.

8. Tatıııoğlu K. Okullarda şiddet ve zorbalık: Risk faktörleri, koruma, önleme ve müdahale hizmetleri: Konya örneği, Bingöl Üniversitesi Sosyal Bilimler Enstitüsü Dergisi 2016;6(12):209-31.

9. Lacey A, Cornell D, Konold T. The relations between teasing and bullying and middle school standardized exam performance. J Earl Adol 2015;37(2):192-221.

10. Atik G. Assessment of school bullying in Turkey: A critical review of self-report instruments. Procedia - Social and Behavioral Sciences 2011;15(4):3232-8.

11. Alikaşifoglu M, Erginöz E, Ercan O, Uysal O, Kaymak DA, İlter O. Violent behaviour among Turkish high school students and correlates of physical fighting. Eur J Public Health 2004;14(3):173-7.

12. Alikaşifoglu M, Erginöz E, Ercan O, Uysal O, Albayrak-Kaymak D. Bullying behaviours and psychosocial health: Results from a cross-sectional survey among high school students in Istanbul, Turkey. Eur J Pediatr 2007;166(4):1253-60.

13. Gültekin Z. Akran zorbalığını belirleme ölçeği geliştirme çalışması 2003; Yüksek Lisans tezi.

14. Kapçı EG. İlköğretim öğrencilerinin zorbalığa maruz kalma türünün ve sıklığının depresyon, kaygı ve benlik saygısı ile ilişkisi. Ankara Üniversitesi Eğitim Bilimleri Fakültesi Dergisi 2004;37(1):1-13.

15. Kepenekci YK, Cinkir S. Bullying among Turkish high school students. Child Abuse Negl 2006;30(3):193-204.

16. Pekel N. Akran zorbalığı grupları arasında sosyometrik statü, yalnızlık ve akademik başarı durumlarının incelenmesi 2004; Yüksek Lisans tezi

17. Pişkin M. Okullarımızda yaygın bir sorun: Akran zorbalığı. 7. Ulusal Psikolojik Danışma ve Rehberlik Kongresi Bildiri Özetleri Kitabı; 2003:125-6.

18. Yıldırım R. Akran zorbalığı. CBÜ Sosyal Bilimler Dergisi 2012;10(2):39-51 
19. Gökkaya F, Sütcü ST. Çocuklar için Zorbalıkla İlgili Bilişler Ölçeğinin geliştirilmesi ve psikometrik özelliklerinin değerlendirilmesi, Anatolian J Psychiatry 2015;16(Special issue 1):54-63.

20. Hymel S, Swearer SM. Four decades of research on school bullying: An introduction. Am Psychol 2015;70(4):293-9.

21. Solberg ME, Olweus D. Prevalence estimation of school bullying with the Olweus bullly/victim questionnnaire. Aggressive Behavior 2003;29(4):239-68.

22. Berger KS. Update on bullying at school: Science forgotton? Developmental Review 2007;27(2):90-126.

23. Hawker DS, Boulton MJ. Twenty years' research on peer victimization and psychosocial maladjustment: A meta-analytic review of cross-sectional studies. J Child Psychol Psychiatry 2000;41(4):441-55.

24. Currie C. Roberts C, Morgan A, Smith R, Settertobulte W, Samdal O, Rasmussen VB (eds). Young People's Health in Context: International report from the HBSC 2001/02 survey. WHO Policy Series: Health policy for children and adolescents. Issue 4, WHO Regional Office for Europe, Copenhagen 2004; 133. [cited 28 Sep 2013]. Available from http://www.euro.who.int__data/assets/pdf_file/0008/110231/e82923.pdf

25. Ercan $\mathrm{O}$, Alikaşifoğlu $\mathrm{M}$, Erginöz $\mathrm{E}$ ve ark. İstanbul lise gençlerinde riskli davranışların sıklığı ve cinsiyete göre dağılımı (Cerrahpaşa Gençlik Sağlığı Araştırması 2000) Türk Pediatri Arşivi 2001;36(2):199-211.

26. Şencan H. Sosyal ve davranışsal ölçümlerde güvenilirlik ve geçerlilik. Ankara: Seçkin Kitabevi; 2005.

27. Olweus, D. Annotation: Bullying at school: Basic facts and effects of a school based intervention program. J Child Psychol Psychiatry 1994;35(4):1171-90. 